\title{
A Novel Wastewater Treatment of Safranine T by Electrochemical Polymerization Method
}

\author{
WANG Junbo ${ }^{1, a}$, WANG Li², CHEN Long ${ }^{1}$, NIU Yujie ${ }^{1}, \mathrm{XIE} \mathrm{Li}^{1}$ and XU Bing ${ }^{1}$ \\ ${ }^{1}$ Huangshan University, Huangshan, Anhui province, PRC \\ ${ }^{2}$ Zhejiang Shuren University, Hangzhou, Zhejiang province, PRC \\ aemail: wangjunbo72@163.com
}

\begin{abstract}
Keywords: Safranine T; Electrochemical polymerization; Decolorization; Kinetics; Intermediates Abstract. In this paper, the target pollutant, safranine $\mathrm{T}$ (ST) was rapidly degenerated by electrochemical polymerization method. Kinetic degradation behaviors and intermediates were also explored by various characteristic techniques. The results showed that the decolorization of ST by electrochemical oxidation was fitted to pseudo first-order reaction. The apparent activation energy was $29.3 \pm 0.63 \mathrm{~kJ} / \mathrm{mol}$. The high resolution UPLC-MS results confirmed that the main reactions included polymerization, oxidative cracking reaction and $\mathrm{N}$-demethylation.
\end{abstract}

\section{Introduction}

Safranine $\mathrm{T}$ (ST) is a commercial dye $\left(\mathrm{C}_{20} \mathrm{H}_{19} \mathrm{ClN}_{4}\right.$ molecular weight: 350.85$)$ which is widely used in staining and biological applications such as large intestine staining, skin staining, color fibers, printed circuit boards, inks and also used in antiseptic preparation. ST will cause some degree of hypersensitivity reactions, carcinogenicity, microbial and fish toxicity [1]. At the same time, its release into environment can impart color to water and increase BOD value. Removal of the dye of ST from wastewater has become a tough issue due to its stable character under harsh condition and biodegradation resistance [2].

Many efforts have been applied to remove ST. One promising technique for organic contaminants degradation is the electrochemical process, which offers several advantages, such as versatility, environmental compatibility and easy automation [3]. In this paper electrochemical polymerization was used to remove ST and test its decolorization kinetics and intermediates.

\section{Experimental}

All chemicals were of analytical grade unless otherwise stated. All were purchased from Shanghai Chemical Reagent Ltd.

A UV-Vis spectrophotometer (UV-2450) was employed to measure the concentration of BG solutions before and after electrolysis. The degeneration efficiency [4] was calculated using the following Eq. (1):

$$
\% E=\frac{\left(A_{i}-A_{f}\right)}{A_{f}} \times 100
$$

Electrochemical experiments were performed with a conventional three-electrode cell using a CHI 660E electrochemical workstation (Shanghai Chenhua, China). The working electrode was Pt disc ( $\Phi 3 \mathrm{~mm}$ diameter), and the counter electrode was platinum foil $\left(2 \mathrm{~cm}^{2}\right)$. A saturated calomel electrode (SCE) was placed in a separate compartment to serve as the reference electrode. Before each test the Pt electrode surface was polished on suede using an aqueous alumina $0.5 \mu \mathrm{m}$ paste, rinsed thoroughly with Milli-Q water and then patted dry using a lint free tissue. The supporting electrolyte was $\mathrm{KCl}$ $\left(\mathrm{C}=50 \mathrm{~g} \cdot \mathrm{L}^{-1}\right)$.

The intermediates were detected by using an UPLC-Qtof-MS (model: Xevo-G2-S-qtof MS, Waters, USA). The column used in all experiments was a Agilent Zorbax-Phenyl stainless steel column of $250 \times 4.6 \mathrm{~mm}$ i.d., $1.7 \mu \mathrm{m}$ particle size (Santa Clara, CA, USA). The mobile phase for the reversed 
mode procedure, used in quantification analysis, was an isocratic mode that uses $0.005 \mathrm{M}$ $\mathrm{CH}_{3} \mathrm{COONH}_{4}$ and $\mathrm{CH}_{3} \mathrm{CN}$ at 50:50 v/v.

\section{Results and discussion}

A UV-Vis spectrophotometer (UV-2100) was employed to measure the characteristic absorption wavelength of ST, and it was $554 \mathrm{~nm}$, shown in Fig. 1. At the same time, the standard absorption curve was tested and was shown in Fig. 2.

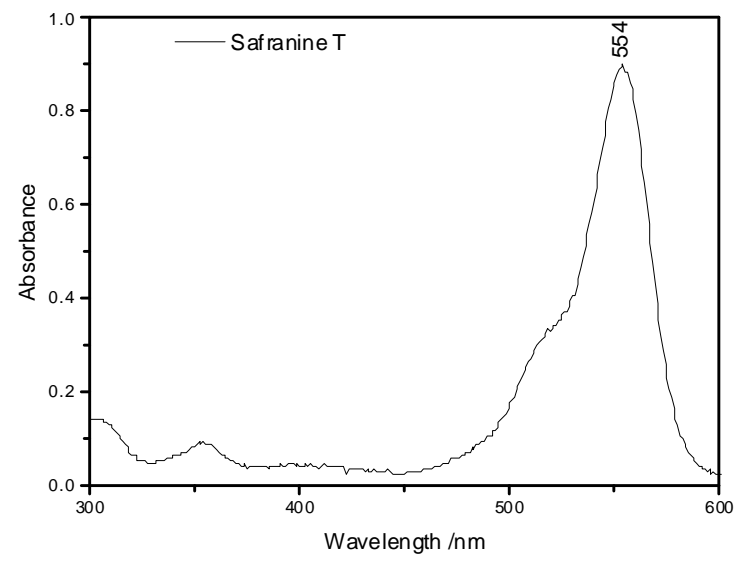

Fig. 1 characteristic absorption wavelength of ST.

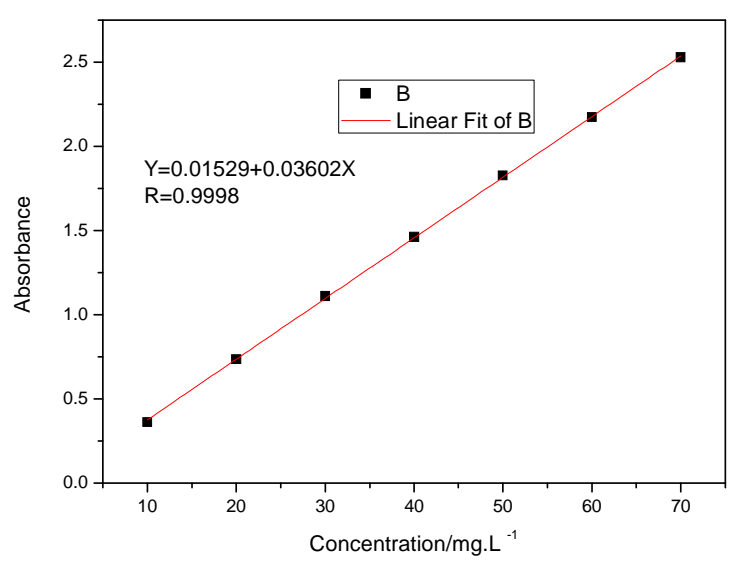

Fig. 2 The standard working curve of ST.

The potentiostatic electrolysis experiments were performed on CHI660E instrument with three electrode glass cell in the temperature range from 293 to $333 \mathrm{~K}$. The electrolysis potential was set at $1.20 \mathrm{~V}$. The dependence of logarithm of ST concentration $\left(\operatorname{lnC}_{0} / \mathrm{C}\right)$ on electrolysis time $(\mathrm{t})$ at various temperatures was obtained. The results were shown in Fig. 3. The good linear relationships illustrated that the decolorization of ST by electrochemical oxidation was fitted to pseudo first-order reactions. The relationship between lnk and 1/T at different temperatures was illustrated in Fig. 4. The apparent rate constant $\mathrm{k}$ values were calculated and the results were shown in table 1 . From table 1, it could be deduced that temperature increasing was helpful for ST decolorization. According to Arrhenius equation [5], the apparent activation energy was calculated as $29.3 \pm 0.63 \mathrm{~kJ} \cdot \mathrm{mol}^{-1}$.

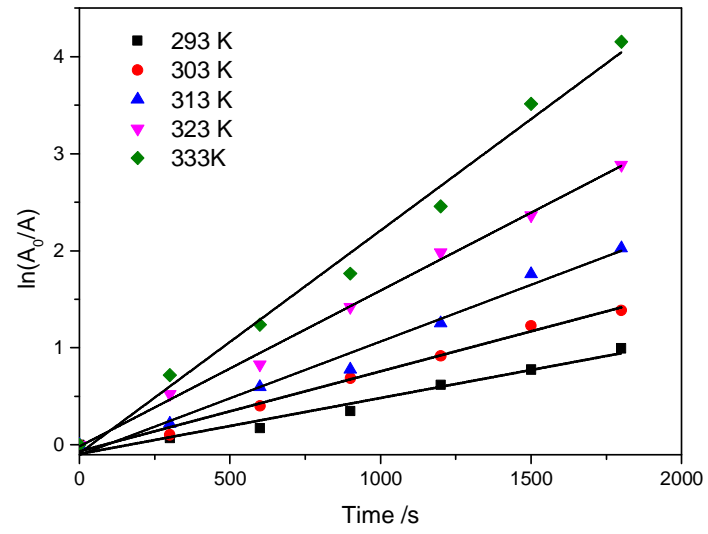

Fig. 3 The linear relationship between $\ln \left(\mathrm{C}_{0} / \mathrm{C}\right)$ and time $\mathrm{t} \quad\left(\mathrm{C}_{0}=100 \mathrm{mg} / \mathrm{L}\right)$

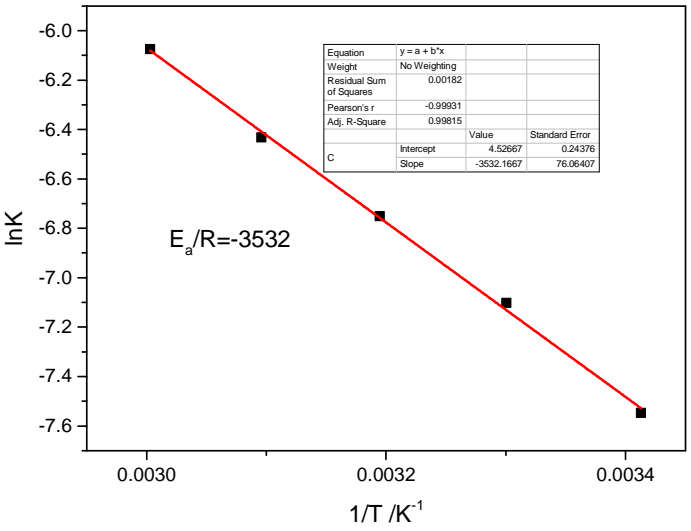

Fig.4 The linear relationship between lnk and 1/T.

Table 1. Apparent rate constant $\mathrm{k}$ values at different temperatures.

\begin{tabular}{llllll}
\hline $\mathrm{T}$ & 293 & 303 & 313 & 323 & 333 \\
\hline $1 / \mathrm{T}$ & 0.00336 & 0.00325 & 0.00315 & 0.00305 & 0.00296 \\
$\operatorname{lnk}$ & -7.54 & -7.10 & -6.75 & -6.43 & -6.07 \\
$\mathrm{k}$ & 0.000527 & 0.000824 & 0.00117 & 0.00161 & 0.00223 \\
\hline
\end{tabular}



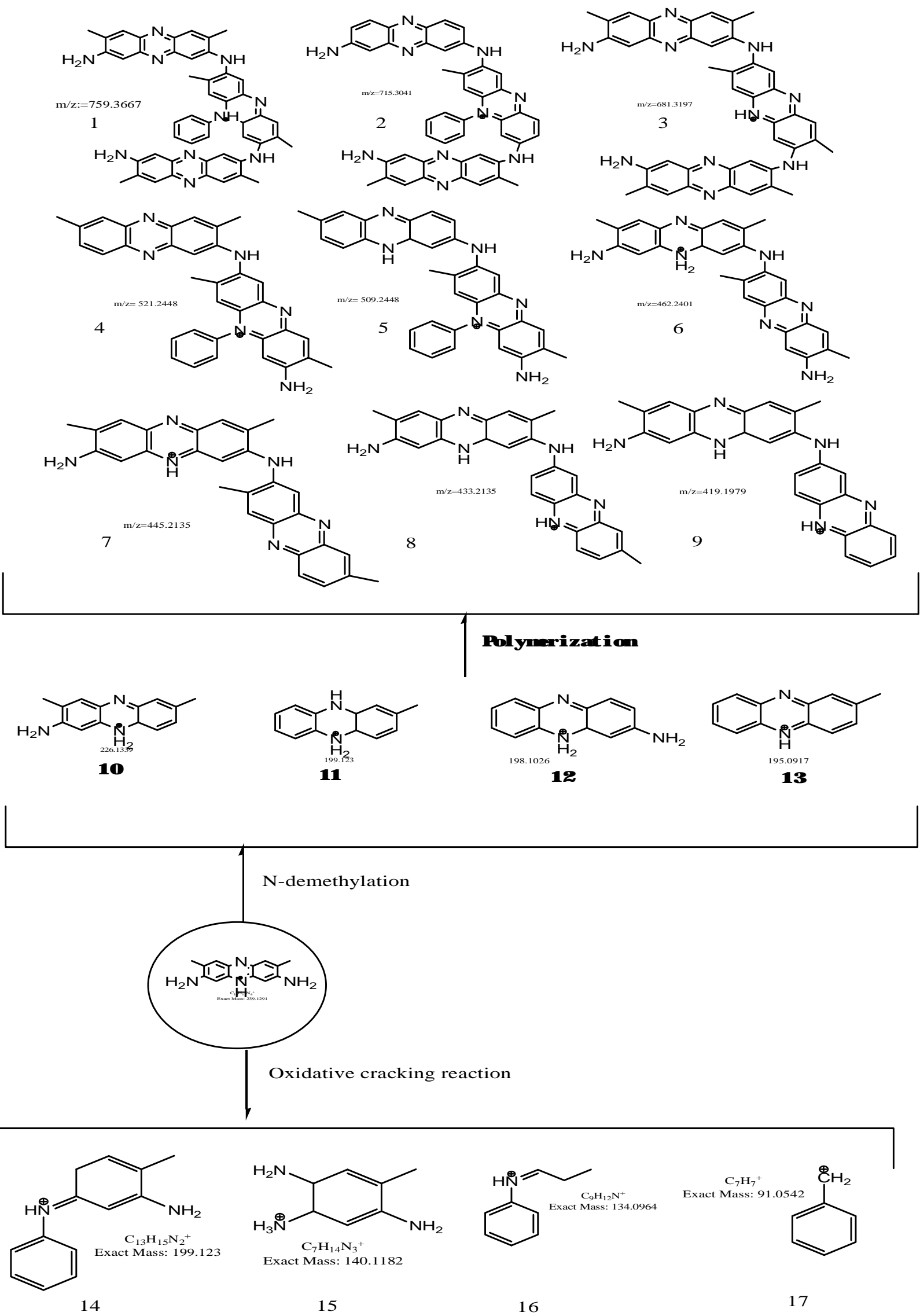

Fig.5 The schematic degeneration path of ST concluded by UPLC-QTOF-MS. 
The intermediates of electro-oxidation of ST could be suggested on the basis of HPLC. The results were shown in Fig.5. It included polymerization, oxidative cracking reaction and N-demethylation.

The potentiostatic electrolysis curve $\left(\mathrm{E}=1.2 \mathrm{~V}_{\mathrm{vs} . \mathrm{SCE}}\right)$ was given in Fig.6. It can be seen that the total electric quantity can be calculated form the current curve integral, the consumed electric quantity $\mathrm{Q}=36.1 \mathrm{C}$, while using common electrolysis method, the theoretical electric quantity $\mathrm{Q}_{\mathrm{T}}$ of full electrochemical oxidation reached $139.5 \mathrm{C}$ according to the equation 2 . The practical consumed electric quantity is greatly decreased due to the sediments of electro-polymerization.

$\mathrm{C}_{20} \mathrm{H}_{19} \mathrm{ClN}_{4}+29.5 \mathrm{O}_{2}=20 \mathrm{CO}_{2}+\mathrm{HCl}+4 \mathrm{HNO}_{3}+7 \mathrm{H}_{2} \mathrm{O}$

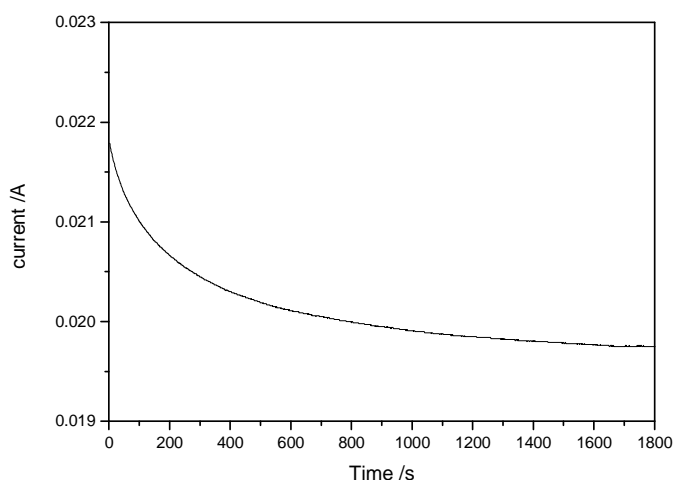

Fig .6 The potentiostatic electrolysis curve of ST in three electrode cell.

\section{Conclusions}

The decolorization of ST by electrochemical oxidation was fitted to pseudo first-order reactions. Activation energy was $29.3 \pm 0.63 \mathrm{~kJ} / \mathrm{mol}$. The intermediates detected by UPLC-QTOF-MS could conclude that the main reactions including polymerization, oxidative cracking reaction and $\mathrm{N}$-demethylation reaction. The practical consumed electric quantity is greatly decreased due to the sediments of electropolymerization.

\section{Acknowledgements}

This work was financially supported by the natural science foundation of Zhejiang province (No. Y5090310, LY14C030004) and Introduce talents project (No. 2015xkjq008).

\section{References}

[1] C.M. A. R Mohamed. J Alloy Compd.Vol. 509 (2011), p. 1648.

[2] S. R. Couto. J Hazard Mater. Vol.148, (2007), p. 768.

[3] C A Martìnez-Huitle, E Brillas. Appl Catal B Environ Vol. 87, (2009), p.105.

[4] G. Charrier, S. Lévy, J. Vigneron, A. Etcheberry, N. Simon. Diam Relat Mater Vol. 20(2011), p. 944.

[5] L Du, J. Wu, C. W. Hu. Electrochim. Acta. Vol. 68, (2012), p. 69. 